\title{
COLECISTITE AGUDA POR ASCARIS LUMBRICOIDES
}

\section{ACUTE CHOLECYSTITES FOR ASCARIS LUMBRICOIDES}

\author{
Amauri Clemente da Rocha, TCBC - $\mathrm{Al}^{1}$; Severino Lourenço da Silva Júnior ${ }^{2}$; \\ Rodrigo Fernando Lourenço de Amorim²
}

\section{INTRODUÇÃO}

A infestação pelo Ascaris lumbricoides representa a principal forma parasitária que acomete a espécie humana ${ }^{1,2}$.

Usualmente este verme se instala na luz intestinal, porém em alguns casos, os vermes podem migrar para outros locais como ductos pancreáticos, ductos biliares, vesícula biliar e apêndice cecal podendo complicar com colangite, colecistite, abscesso hepático, pancreatite, apendicite ${ }^{2}$.

A ascaridíase das vias biliares, embora rara, constitui-se na mais frequiente ascaridíase ectópica sendo mais raramente encontrada na vesícula biliar ${ }^{2}$

O objetivo deste trabalho é relatar um caso de colecistite aguda por Áscaris com revisão da literatura.

\section{RELATO DO CASO}

Paciente sexo masculino, 35 anos, pardo, atendido no Ambulatório de Cirurgia Geral do Hospital Geral Severiano da Fonseca (Sanatório) com dor no quadrante superior direito do abdome irradiando-se para o dorso, acompanhada de vômitos e febre há três dias. Referia dores semelhantes anteriormente. Ao exame apresentava-se com bom estado geral. Abdome apresentava-se doloroso no hipocôndrio direito e epigástrio, sem irritação peritoneal e com sinal de Murphy presente.

A ultrassonografia (US) do abdome evidenciou vesícula biliar com espessamento dA parede e um Ascaris lumbricoides no seu interior. Apresentava-se com discreta leucocitose (12.000 leucócitos) sem desvio à esquerda; endoscopia digestiva alta sem alterações.

Foi realizada colecistectomia convencional na qual foi detectada a presença de verme morto no interior da vesícula biliar (Figura 1). Iniciou-se antibioticoterapia com cefalotina duas horas antes da cirurgia até o $3^{\circ}$ dia de pós-operatório. $\mathrm{O}$ paciente recebeu alta hospitalar no $4^{\mathrm{O}}$ dia de pós-operatório sendo tratado com albendazol $400 \mathrm{mg}$ por três dias.

\section{DISCUSSÃO}

A invasão das vias biliares por Ascaris é justificada por alguns autores como uma tendência dos vermes em penetrar em pequenos orifícios ${ }^{3}$. No entanto, é raro haver invasão da vesícula biliar devido à tortuosidade e ao diâmetro reduzido do ducto cístico ${ }^{1,4}$. O diagnóstico pode ser feito durante a cirurgia ou através da US ou colangiopancreatografia endoscópica retrógrada $(\mathrm{CPRE})^{4}$.

O quadro clínico da ascaridíase biliar quase sempre assemelha-se a outras colecistopatias, sobretudo as litiásicas ${ }^{3}$. $O$ paciente apresenta-se com dor no quadrante superior direito, por vezes associada a febre, vômitos e icterícia ${ }^{3}$. No presente caso, o paciente apresentou todos estes sinais e sintomas exceto icterícia.

A ultrassonogria da vesícula biliar com ascaridíase pode revelar espessamento da parede, imagem linear ecogênica sem sombra acústica, com ou sem movimentos e uma fina linha hipoecogênica ${ }^{4}$. Neste caso a US evidenciou imagem cilíndrica ecogênica bem definida com três camadas, sem movimento e vesícula de parede espessada contendo um Ascaris.

A CPRE representa o exame de maior sensibilidade, além do seu papel terapêutico na remoção endoscópica do verme nas vias biliares ${ }^{3,4}$. No entanto, este método é mais caro, tecnicamente mais difícil, invasivo, mais demorado e requer anestesia geral em pacientes pediátricos (percentagem maior da população infectada $)^{4}$. A US é o exame de escolha no diagnóstico de ascaridíase biliar, particularmente da vesícula biliar. A CPRE fica reservada para os casos em que a US não foi conclusiva, tendo então sua indicação propedêutica e terapêutica ${ }^{4}$.

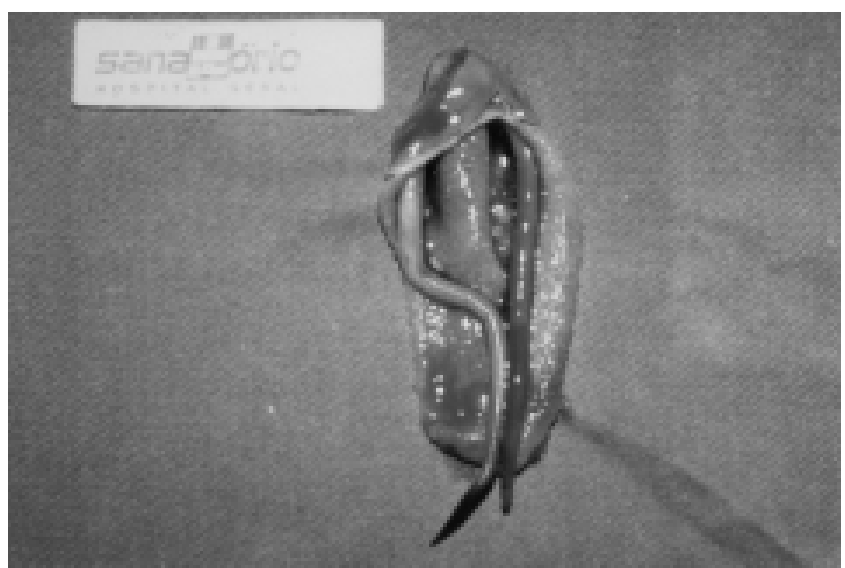

Figura 1 - Ultrassonografia mostrando imagem cilíndrica inerte dentro da vesícula biliar.

1. Professor de Anatomia Humana da Universidade Federal de Alagoas e Escola de Ciências Médicas de Alagoas; Cirurgião do Hospital Geral Severiano da Fonseca.

2. Acadêmico do Curso de Medicina da Universidade Federal de Alagoas.

Recebido em 18-01-05

Aceito para publicação em 18-01-05

Trabalho realizado no Serviço de Cirurgia Geral do Hospital Geral Severiano da Fonsêca, Maceió - AL. 
O tratamento preconizado para ascaridíase das vias biliares consiste na administração de drogas anti-helmínticas e a remoção do verme por via endoscópica ou cirúrgica ${ }^{5}$. No caso da colecistite por áscaris o tratamento de eleição é a colecistectomia , convencional ou laparoscópica ${ }^{5}$. A abordagem laparoscópica é melhor que a convencional por diminuir o período de hospitalização e a morbidade pós-operatória ${ }^{5}$. A terapia com drogas anti-helmínticas pode ser feita antes ou depois da cirurgia 5 .

No presente caso, o paciente foi submetido à colecistectomia convencional devido à falta de disponibilidade de equipamento de videolaparoscopia no serviço na época da cirurgia, complementado posteriormente com tratamento clínico evoluindo de forma favorável.

\begin{abstract}
Biliary's ascariasis is the most often ectopic site of this helminthiasis, but invasion of the worms into the gallbladder is quite rare. The autors report a case of a patient with clinical symptoms, compatible with cholecystitis induced by the worm, as shown by ultrasonography. Treatament was cholecystectomy and antihelmintic drug therapy with a good outcome (Rev. Col. Bras. Cir. 2006; 33(4): 262-263).
\end{abstract}

Key words: Gallbladder diseases; Gallbladder diseases/parasitology; Ascaridiasis/ultrasonography; Ascaridiasis/diagnosis; Ascaridiasis/therapy; Cholecystitis.

\section{REFERÊNCIAS}

1. Gómez NA, Ortiz O, León CJ, Iñiguez S. Ascariasis de la vesícula biliar; reporte de dos casos y revisón de la literatura. Acta Gastroenterol Latinoam. 1992;22(2):129-31.

2. Bromberg SH, Waisberg J, Okagawa T, Barreto E, Franco MIF, Torres LCC, Godoy AC. Ascaridíase das vias biliares. Folha Méd. 1996; 112(2):167-71.

3. Ozsarlak O, De Schepper AM, De Backer A, Fierens H, Pelckmans PA. Diagnostic and therapeutic role of ERCP in biliary ascariasis. Rofo. 1995;162(1):84-5.

4. Filice C, Marchi L, Meloni C, Patruno SF, Capellini R, Bruno R. Ultrasound in the diagnosis of gallbladder ascariasis. Abdom Imaging. 1995;20(4):320-2.
5. Yoshihara S, Toyoki Y, Takahashi O, Sasaki M. Laparoscopic treatment for biliary ascariasis. Surg Laparosc Endosc Percutan Tech. 2000;10(2):103-5.

Como citar este artigo:

Rocha AC, Silva Jr SL, Amorim RFL. Colecistite aguda por áscaris lumbricoides. Rev Col Bras Cir. [periódico na Internet] 2006 JulAgo;33(4). Disponível em URL: http://www.scielo.br/rcbc

Endereço para correspondência:

Amauri Clemente da Rocha

Loteamento Terra de Antares I, Quadra 43, nº 06 - Serraria 57045-180 - Maceió - AL

E-mail: amauri.rocha@uol.com.br 